\title{
The Rational Construction of Vocational Education and Social Level
}

\author{
Rong Mao
}

Vocational and Technical College, Gansu Open University, Lanzhou; Gansu, 730030, China

$$
\text { 364221500@qq.com }
$$

Keywords: Vocational education; Social level; Construction

Abstract. China's education has gradually changed from traditional pure academic education to rational vocational education. Vocational education has been a kind of object that accompanies the academic education, and its meaning is very deep. We should enhance the intensity of vocational education, especially the higher vocational education, and make ordinary laborers at the middle level become professional people who have received higher education and have professional quality. Forming a reasonable social level can promote the harmonious and sound development of the society.

Acknowledgements: This research is supported by the following projects: The general project of philosophy and social science planning project of Gansu in 2015 "Research on the Development and Construction of Characteristic Educational Resources in Gansu Minority Areas"(NO: YB017), "Research on the Application of Electronic Learning Portfolio to Promote the Teaching Effect”(NO:2014JG-2670030634).

\section{职业教育与社会层级合理建构 \\ 毛荣 \\ 甘肃广播电视大学 职业技术学院，中国 甘肃兰州 730030 \\ 364221500@qq.com}

摘要: 中国的教育逐渐从传统的纯粹学术教育向合理的职业教育方向改革, 职业教育已经作为一种伴随着学术教育的客 体而存在，其意义非常深广。加强职业教育尤其是高等职业教育的力度，使中间层级的普通劳动者成为接受过高等教育具有 专业素质的职业人，形成合理社会层级能促进社会的和谐良性发展。

关键词: 职业教育; 社会层级; 建构

中图分类号: G718 文献标志码：A

中图分类号: G718 文献标志码：A

\section{1 教育的发展与职业教育发展的趋势}

教育是小到关系一个家庭的稳定，大到关乎国家的兴旺衰落的直接问题。我们现在所关注的教育意味 着的是我们整个民族的发展。教育事业是从幼儿园到大学的一个整体过程，那么培养什么样的人才为社会 服务就是一个值得深思的问题。人才的质量是社会的教育所决定的, 教育是为一个特定的社会提供所需要 的人才, 这就要求教育时刻紧跟着社会发展的脚步, 教育的成败也是要在社会的发展实践中进行检验的 [1]。现在的教育所要培养的不是读死书的所谓 “天才” 而是能为目前这个我们所处的社会做出贡献的人。 依照当下的发展历程很明显教育是要培养出一批具有知识与思辨能力以及实际操作协同能力的人。中国乃 
至世界目前教育的实际意义就是为培养能够帮助此时代的社会极力进步的人。大学教育就相对有一定的指 向性, 为培养每一区域的人才而做出计划和教学大纲。大学的教育是现代社会最应该完善的教育体系, 在 知识与个人发展的观念形成的最成熟时期, 大学教育就显得尤为重要。而教育的实际意义在这个阶段也已 经完全显露 [2]。

尽管中国的教育一直在不断的学习进步, 但是我们的教育模式还是有欠缺。相较于西方的教育机制或 者说其他的发达国家还是有很多的不足。教育没有完美这样的概念, 只有趋于完善。本文章着重谈的是中 国的教育所培养出的人群层级的分属问题。就是教育中或者说是经历了高等教育从教育中收益的那一部分 人, 导致了受精英高等教育者的群体几乎都是高收入, 具有一定的社会地位, 加之客观存在的教育资源分 布不公的问题, 拉大了那些接受较低层地教育或只受过基础教育群体的人之间的距离, 客观上形成一定的 社会层级。

教育的目的是培养一批对社会有用的人, 但绝不是完全的精英模式的人。社会的发展是需要平衡与稳 固的, 而教育更是要尊重每一个正常的人的发展历程与属性。精英模式会让社会的价值观也由此变成崇尚 代表 “先进” 的那一小部分人。而这一小部分人所获得的社会的尊重会变成一种高级的层级而存在。从而 就会被几乎所有的普通的层级所争相追逐, 也会导致社会的机制的不平衡性, 以及价值观的扭曲, 更会导 致社会层级的存在模式的单一化。从而社会的教育资源分布不平衡就会加剧, 固化层级不利于社会的和谐 发展 $[3]$ 。

职业教育的发展就是对于上述问题的一个很好的解决途径。随着改革开放经济的发展中国社会层级具 有多样性。社会层级的重新划分与建构增加了职业的多重性, 打破了之前单一的职业线条。职业的多样化 复杂化专业化也要求社会的教育系统能够适时提供相应的专业人才, 职业教育的重要性日益显现。从上世 纪 90 年代开始我国高等职业教育规模开始扩充, 高等职业教育作为一种教育类型, 有着不同于普通学术 教育的意义 $[4]$ 。

加大职业教育的发展广度已经是一种必然的趋势, 是教育使命的价值取向使然。叶澜教授认为: “价 值取向是人对客观事物及自己需求和利益的认识水平的反映, 也是人的主观意志的体现。” [5]这一认识 存在于对事物 “价值” 认识背景下, 关注的是 “人” 对事物和自己的认识。高等职业教育的切实指向就是 以人的生命需要为基础, 人的发展的多样性就要求教育决不能是仅仅单一的形式, 更大程度上应当尊重人 的自身的发展规律, 职业教育的设定是培养既满足社会需求又满足个性需求的教育模式。人的发展是职业 教育发展的现实和最终目的。既要依靠人的发展来发展职业教育, 更要为了人的发展而发展职业教育, 并 且使职业教育的发展的成果惠及所有的人。目前中国社会, 正处于经济全球化的背景之下, 通过城市 (镇) 化 实现现代化的过程, 政府致力于经由各种教育把中国这个人力资源大国发展成为人力资源强国, 维持目前 快速增长的经济速度, 而职业技术教育与培训, 对人力资源的有效开发具有重要的作用。

职业教育是为了培养更多的各方面的人才, 是为了平衡层级的社会属性。这也是由职业教育的内涵所 决定的, 首先职业教育作为教育类型, 有着不同于普通教育而富含职业教育根本属性, 这正是职业教育的 基本内涵 [5]。职业教育内涵体现了教育观念变更：基于现代的地球村的多元智能的人才观需求，世界的 发展要求各类人才的发展, 而同时个人的发展也是智能化的不是单一的, 每个人智力都是在不同的维度上 有所长, 将每个人的智能激发培养出来是非常重要的; 全面发展的能力观, 普通教育重在个性发展的需求 
上, 其目标是内隐的, 而职业教育重在社会发展的需求, 其目标是外显的职业教育的社会功能是培养生产、 服务和管理第一线的应用型职业人才, 职业教育也是适应社会的发展, 顺应社会发展规律, 满足社会需求 造就合格的 “职业人”。作为教育事业的重要组成部分, 职业教育的教育功能则体现为还要适应个性发展, 遵循教育发展的规律, 为满足个性需求塑造合格的 “社会人”, 职业教育注重培养社会人完善内在人的品 格 [6]。职业教育是在基于遵照了社会的发展以及人的发展的需求, 对于社会和人的发展是有着不可替代 的作用, 促进了社会层级的发展与完善。

\section{2 职业教育与社会层级构建之间的关系}

教育是人才培养的主要方式, 现代社会的人才基础几乎都是来源于各个学术理念与实践相结合的一个 综合性的教育模式。随着高等教育的改革与发展, 职业教育的广度和深度在一定程度上有所发展, 促进社 会层级的演变与分化。而这样的广度和深度造就了一批新的 “职业人”, 出现了很多新兴的产业。在经济 全球化的进程中，通过教育或者社会分化产生了现代意义上的新的社会层级 [7]。中国从 “十六大” 就确 定了社会中出现了一些新兴的社会层级, 如民营科技企业的创业人员和技术人员、受聘于外资企业的管理 技术人员、个体户、私营业主、中介组织的从业人员、自由职业人员等。中国原来的 “两个阶级、一个层 级” (工人阶级、农民阶级和专业技术人员层级) 的社会结构发生了重大变化。在工人阶级内部, 分化形成 了国有企业、城镇集体企业, 工人层级和企业管理者层级以及雇佣工人层级、失业半失业工人群体, 还有 私营企业主、个体劳动者层级等。我国通过职业教育而新兴的层级, 在现实社会生活中最明显的特征是拥 有较高的收入, 同时也拥有较高的社会地位。据调查显示, 在我国社会地位最高的是专业技术人员层级, 国 家与社会管理者层级和经理人员层级, 其次是私营企业主层级和办事人员层级。显而易见, 新兴层级人员均 排在前列。而且, 随着工业化的高速发展, 中国全球化加深, 专业技术人员层级的经济地位又会进一步上升, 经济地位的上升势必会造就其社会地位的再一次被认可。高等职业教育中培养的相对比较多的是专业技术 与管理层级。对于这一层级的人来说, 他们的利益诉求更多的是依靠社会给予一个公平竞争的环境, 使每个 社会成员的地位层次都可能通过自己的努力而得到改变, 或者使其地位层次可以自动跨越 [8]。高等职业教 育使得社会的层级更加的丰富与完善, 同时这些层级在社会发展中也具有一定的调节作用, 社会的层级是 在不断的发展中变化的，而职业教育调节社会的层级更加的趋于合理化。同时更多的普通职业教育深入到 城乡地区, 用知识装备更多的普通劳动者群体, 使其在社会中的层级属性不再是最低下的, 并且通过接受 教育让其在社会生存中对层级会有全新的自我认识, 从主观上改变对之前陈旧的层级概念的认知。职业教 育的意义是让更多的人去追求通过努力就能获取的层级地位, 使得社会层级的建构灵活化, 同时平衡了社 会的身份地位分割。

职业教育之下新兴的层级在社会中代表着先进的生产力, 这些层级的完善是对整个社会的一个全新的 组合, 使社会的发展更加的接近自然的属性, 减少其矛盾的冲突。新兴的大多中间层级的力量也在试图的 使更多的低一层群体用职业技能来装点自己以求达到更高的层次。新兴的层级在社会上的认可程度以及积 极影响也让教育得到反思, 社会出现的新兴的层级决定了其职业的多样性, 对教育提出了多样性的要求, 促进了职业教育的发展, 促进了教育的改革 [9]。

\section{3 职业教育的发展与社会层级合理建构的意义}

社会公平与正义是衡量社会全面进步的重要尺度, 是人类文明进步的首要标志, 更是人类社会长久以 
来的价值追求, 社会的公平与正义是对于我们建立和谐社会的一个必要条件。自古都有不少的学者在探讨 正义与公平, 柏拉图在《理想国》中指出: 正义就是每个等级的人都应该在城邦 (国家) 中执行最适合个人 的本性的事情, 不去干涉他人。亚里士多德也认为, 公平就是公正、平等, 他强调公正是一切德行的总汇。 他在《政治学》一书中指出: “政治学上的善就是正义, 正义以公共利益为依归。按照一般的认识, 正义是 某种事物的平等观念。” [10]在古罗马, 著名的思想家、政治学家西塞罗认为, 正义就是 “使每个人获得其 应得的东西的人类精神意向”。职业, 作为收入的最重要来源, 与所处的社会阶级、层级地位有着直接的联 系, 也隐含着对他人的某种程度上的权力, 依靠组织资本 (即管理权力) 和文化资本 (即专业技能) 来获取其 社会地位而并非是占有生产资料。随着中国现代经济的不断发展, 经过职业教育获得专业的技能, 进而获 得了理想的薪资与相应的社会地位。

社会层级的合理构造是社会和谐的保障。学术界一般都认可社会结构可以分为上、中、下三个层级, 在和谐社会里层级和谐最为重要, 社会发展过程中层级产生不可避免的, 多元化的发展, 必然产生利益主 体的多元化, 不同层级有不同的利益, 包括经济利益, 政治利益, 区域之间, 文化之间甚至有相对对立的 情况。固化的社会层级会加重社会矛盾, 引发社会动荡。从历史上看, 很多剧烈的社会动荡是由于阶层固 化加剧了社会矛盾引起的, 当社会动荡打破了固化的社会层级结构, 层级间得到了流动, 缓和了层级间的 利益冲突。因此社会结构层级合理建构就体现为层级和谐就是要调整不同层级的利益, 形成层级间合理的 流动。教育在社会层级流动中起着重要的作用, 尤其是高等教育起到作用日趋重要。现代社会发展使得利 益主体细化, 层级也多元化, 第一产业、第二产业和第三产业的发展比例也发生了变化。因此对教育也提 出细化和细分的要求。学术界普遍认可, 中间大, 两头小的 “橄榄形” 社会层级模式是比较合理的, 庞 大的中间层级的社会具有一定稳定性。因此从中间层级入手, 扩大中间层级, 建立合理的社会结构能促进 社会的可持续发展。学者普遍认为教育教育分流层次结构和社会层级结构具有一定的对应关系。细化的社 会分工需要细化的职业人, 职业教育在很大程度上直接加大了中国社会中间层级的力量。中间层级的普通 劳动者是已经被教育指导过的具有专业性质的职业人, 中间层级实现自我主体的价值, 赢得了社会认可。 这些广大中间层级势必会下潜亦或是延伸到社会的各个领域部门, 这样他们带去的就不是简单的普通劳动 者的被尊重而是有利于整个社会的公平与正义, 他们自身的发展的趋势又促进了全社会的公平性, 有利于 社会结构的稳定。[11]

“十九大” 指出, 我国进入了中国特色社会主义进入新时代, 社会主要矛盾已经转化为人民日益增长 的美好生活需要和不平衡不充分的发展之间的矛盾。社会主要矛盾转化集中反映出我国社会发展新的阶段 性特征, 而加大职业教育, 发挥高等职业教育分流作用, 对于缓解我国社会矛盾, 传播社会核心价值观, 形成社会共同意识, 促进社会和谐发展有着重要的现实意义。

\section{致谢}

此项研究受到以下项目支持: 2015 年度甘肃省哲学社会科学规划项目一般项目 “甘肃民族地区特色教 育资源开发与建设研究” (NO: YB017); “运用电子学档促进教学效果的研究” (NO:2014JG-2670030634)

\section{参考文献:}

[1] 姜大源. 职业教育学研究新论 [M]. 北京: 教育科学出版社, 2007：122.

[2] 郑永扣. 大学发展战略: 理念、目标与管理 [M]. 北京: 人民出版社, 2006：241. 
[3] 刘少雪, 张应强. 高等教育改革: 理念与实践 [M].上海：上海交通大学出版社, $2007: 141$.

[4] 梁艳清, 杨朝晖, 侯维芝. 关于发展本科层次高等职业教育的几点思考 [J]。教育与职业, 2006 (2)： $5-7$.

[5] 王建华. 高等教育的理想类型 $[J]$ 高等教育研究，2010，（1）：1-9.

[6] 凌小萍. 新兴层级研究综述 [J]兰州学刊, 2005（3）：229-231.

[7] 彭拥军, 蓝泽芳. 促进合理社会分层流动是高等教育改革的重要目标 $[\mathrm{J}]$ 教育研究与实验, 2011 (5) : 7-11.

[8］王 永. 从高等教育分层看如何提升我国高职教育的地位 $[J]$ 职业教育研究，2006（12）：9-11.

［9］陶能祥. 教育流层结构与社会层级结构的对应关系 [J] 职业技术教育，2005（1）：11-13.

[10］姜裕富.社会分层理论与和谐社会的构建 $[J]$ 攀 登, 2005（5）：12-14.

[11］董泽芳, 陈新忠. 高等教育分流影响社会分层流动的实证研究 [J] 华中师范大学学报, 2013（9）: $147-153$.

\section{References}

[1] D.Y.Jiang: New Theory on the Study of Vocational Education[M], Beijing: Educational Science Publishing House, 2007: 122.(In Chinese)

[2] Y.K.Zheng: University Development Strategy: Concept, Goal and Management[M], Beijing: People's Publishing House, 2006: 241.(In Chinese)

[3] S.X.Liu and Y.Q.Zhang: Higher Education Reform: Concept and Practice[M], Shanghai: Shanghai Jiao Tong University Press, 2007:141.(In Chinese )

[4] Y.Q.Liang, C.H.Yang and W.Z.Hou: Some Thoughts on the Development of Higher Vocational Education at the Undergraduate Leve1[J], Education and Vocation, 2006(2): 5-7.(In Chinese)

[5] J.H.Wang: Ideal Types of High Education[J], Journal of Higher Education, 2010, (1): 1-9.

[6] X.P.Ling: A Review of the New Level of Research[J], Lanzhou Academic Journal, 2005(3): 229-231.(In Chinese)

[7] Y.J.Peng and Z.F.Lan: Promoting Reasonable Social Stratification and Mobility is an Important Goal of the Reform of Higher Education[J], Educational Research and Experiment, 2011(5): 7-11.(In Chinese)

[8] M.Wang: How to Improve the Position of Higher Vocational Education in China from the Level of Higher Education[J], Vocational Education Research, 2006(12): 9-11.(In Chinese)

[9] N.X.Tao: The Corresponding Relationship of the Educational Delamination Structure and Social Class Structure[J] Vocational and Technical Education, 2005(1): 11-13.

[10] Y.F.Jiang: The Construction of the Social Stratification Theory and the Harmonious Society[J], Asoent, 2005(5):12-14.(In Chinese)

[11] Z.F.Dong and X.Z.Chen: Empirical Research on the Influence of Higher Education Shunt on Social Stratification Mobility[J], Journal of Huazhong Normal University, 2013(9): 147-153.(In Chinese) 